\title{
Wedge gastroplasty and reinforced crural repair: Important components of laparoscopic giant or recurrent hiatal hernia repair
}

Bryan A. Whitson, MD, Chuong D. Hoang, MD, Adam K. Boettcher, Peter S. Dahlberg, MD, PhD, Rafael S. Andrade, MD, and Michael A. Maddaus, MD

Earn CME credits at http:// cme.ctsnetjournals.org

Supplemental material is available online.
From the Department of Surgery, Section of Thoracic and Foregut Surgery, University of Minnesota, Minneapolis, Minn.

Received for publication May 8, 2006; revisions received June 20, 2006; accepted for publication July 12, 2006.

Address for reprints: Michael A. Maddaus, MD, University of Minnesota Department of Surgery, MMC 207, 420 Delaware St SE, Minneapolis, MN 55455 (E-mail: madda001@umn.edu).

J Thorac Cardiovasc Surg 2006; 132: 1196-1202

$0022-5223 / \$ 32.00$

Copyright (๑) 2006 by The American Association for Thoracic Surgery

doi:10.1016/j.jtcvs.2006.07.007
Objective: Laparoscopic repair of a giant hiatal hernia ( $>50 \%$ of the stomach above the diaphragm) is associated with short-term recurrence rates of $12 \%$ to $42 \%$. Recurrent hiatal hernias often have significantly altered anatomy, making laparoscopic repair challenging. We hypothesized that increasing intra-abdominal esophageal length by means of Collis wedge gastroplasty, complete fat-pad dissection, hernia-sac excision, and primary reinforced crural repair would minimize short-term recurrence and provide adequate symptomatic relief.

Methods: From January 1, 2001, though May 1, 2005, 61 patients underwent laparoscopic repair of a giant or recurrent hiatal hernia with a Collis wedge gastroplasty and Nissen fundoplication. Symptomatic outcomes were assessed with a validated questionnaire (Gastroesophageal Reflux Disease Health-Related Quality of Life). We obtained postoperative radiographic imaging to objectively assess anatomic results at a median of 1.13 years.

Results: Of the 61 patients, $12(20 \%)$ were referred to our institution after previous repairs. Operating time averaged $308 \pm 103$ minutes. The median hospital stay was 4 days. Postoperative complications occurred in $5(8.2 \%)$ patients. One $(1.6 \%)$ patient died of cardiac complications. Postoperatively, 52 (85\%) patients completed the questionnaire with mean a Gastroesophageal Reflux Disease Health-Related Quality of Life questionnaire score of $1.15 \pm 2.78$ (scale, $0-45 ; 0=$ asymptomatic). Overall, 51 (98\%) of the 52 respondents were satisfied with their surgical outcome. Postoperative radiographic data were available for $54(89 \%)$ patients. We identified no recurrences at 1-month follow-up, and only $4.7 \%$ (2/42) had evidence of radiographic recurrence at 1 year or more.

Conclusions: Consistent use of a Collis wedge gastroplasty with reinforced crural repair minimizes short-term recurrence after minimally invasive giant hiatal hernia repair. Symptomatic results are excellent in most patients.

$\mathrm{T}$ oday, laparoscopic Nissen fundoplication can be performed with a $0.35 \%$ rate of reoperation for failure. ${ }^{1}$ However, reports of laparoscopic repair of giant hiatal and paraesophageal hernias without a Collis gastroplasty have been disappointing, with short-term recurrence rates ranging from $12 \%$ to $42 \%{ }^{2-4}$ Open repair of giant hiatal and paraesophageal hernias coupled with Collis gastroplasty and fundoplication have yielded excellent long-term results, leading some authors to advocate an open approach for these patients. ${ }^{5,6}$

In an effort to minimize the potentially high short-term recurrence rates associated with laparoscopic repair of giant hiatal hernias, we undertook a systematic technical approach to the operation, emphasizing whenever possible the application of the same methods of an open repair, as delineated by Pearson and colleagues, ${ }^{5,7}$ but performed laparoscopically. The purpose of our study was to evaluate our 


\begin{tabular}{|ll|}
\hline $\begin{array}{ll}\text { Abbreviations and Acronyms } \\
\text { 3-D CT }\end{array}$ & 3-dimensional computed \\
& tomographic scan \\
EEA & end-to-end anastomosis \\
EGJ & $=$ esophagogastric junction \\
GERD-HRQOL = & Gastroesophageal Reflux Disease \\
& Health-Related Quality of Life \\
GIA & $=$ gastrointestinal anastomosis \\
VBE & $=$ video barium esophogram \\
&
\end{tabular}

short-term outcomes in patients undergoing laparoscopic Collis-type wedge gastroplasty and Nissen fundoplication (Collis-Nissen) repair with respect to both the physical repair and patients' symptom relief.

\section{Materials and Methods}

\section{Patients and Statistical Analysis}

The Institutional Review Board at the University of Minnesota approved this retrospective study. We reviewed charts of all patients who underwent a minimally invasive Collis-Nissen wedge gastroplasty from January 1, 2001, through May 1, 2005. These operations were performed on the Thoracic and Foregut Surgery Service at the University of Minnesota Medical Center. We gathered preoperative information on patient characteristics and their symptoms, video barium esophogram (VBE) findings, and data on gastric emptying, manometry, $\mathrm{pH}$ monitoring, and esophagogastroduodenoscopy.

After the operation, we evaluated patients' quantitative symptomatic outcome with the validated Gastroesophageal Reflux Disease Health-Related Quality of Life (GERD-HRQOL) questionnaire (Table E1). ${ }^{8,9}$ The GERD-HRQOL questionnaire contains 9 questions, with individual scores of 0 to 5 and a composite score of 0 (best) to 45 (worst). Composite responses to the GERDHRQOL questionnaire are grouped as excellent (0-5), good (6-10), fair (11-15), and poor (>15). Additionally, we obtained a postop-

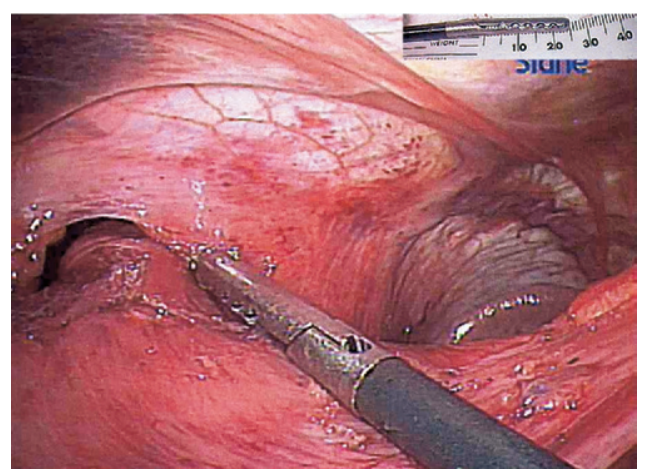

Figure 1. Image from Figure E2 with tension now removed. The length of the intra-abdominal esophagus is measured with the grasper (the grasper end is $2.5 \mathrm{~cm}$ in length [inset). Intra-abdominal esophageal length is inadequate $(<2.5 \mathrm{~cm})$.

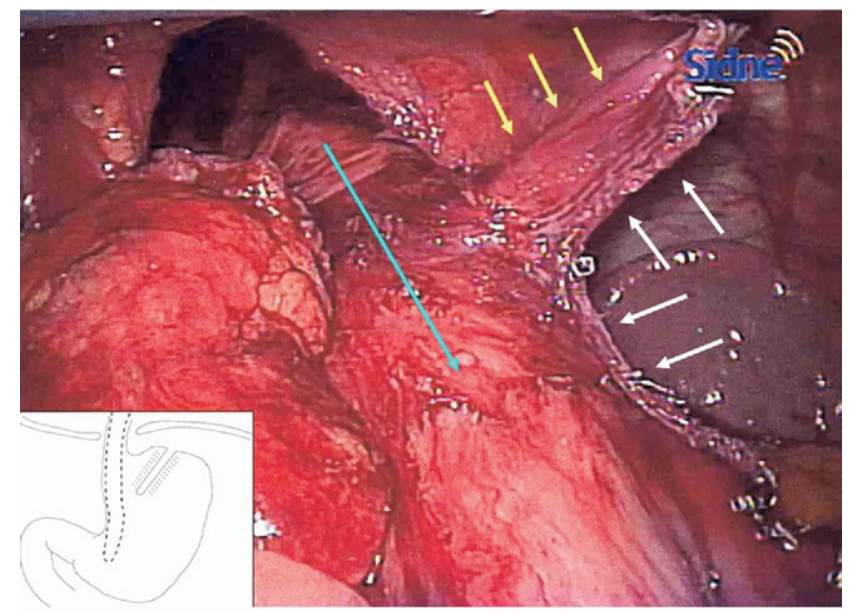

A

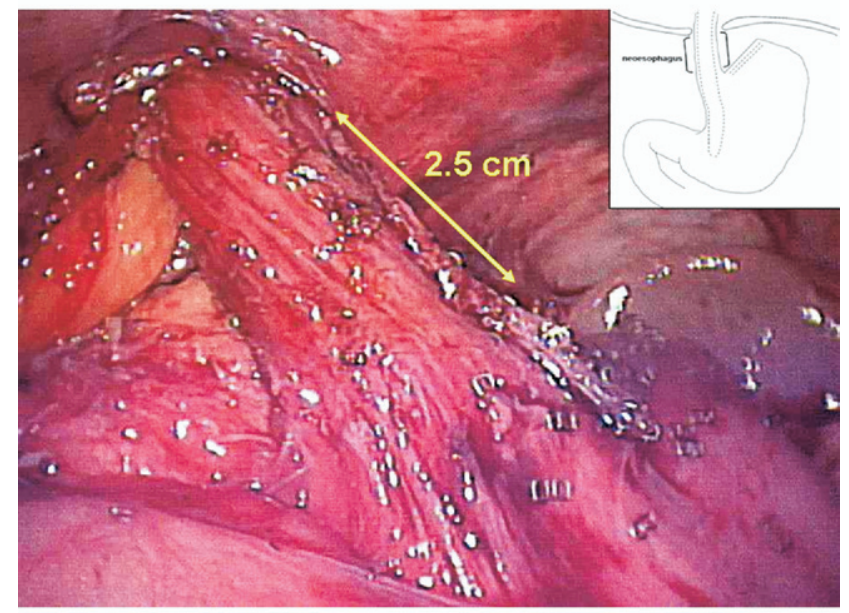

B

Figure 2. A, The staple line (white arrows) has been completed and brought snuggly to the edge of the dilator (blue arrow). The yellow arrows point to the wedge of fundus to be resected. B, Completed Collis wedge gastroplasty with no tension applied, demonstrating ample intra-abdominal length (yellow arrow). Line drawing insets are presented for visualization. ${ }^{10}$

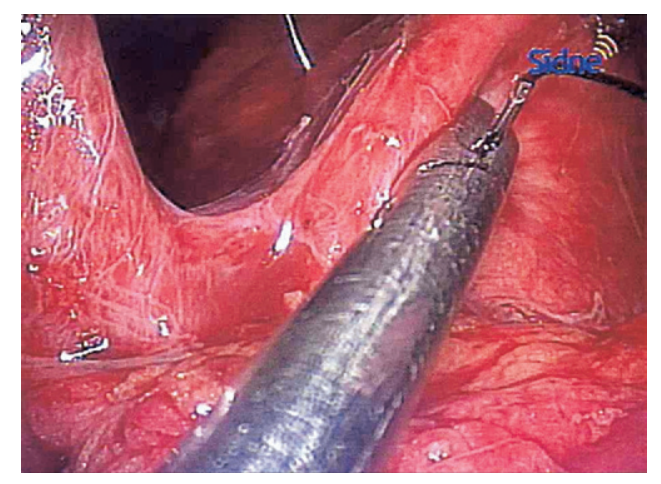

Figure 3. Placement of crural stitches. 
TABLE 1. Patient characteristics

\begin{tabular}{lrc}
\hline Procedure & $\mathbf{n}$ & $(\%$ of 61$)$ \\
Gastrointestinal anastomosis wedge & 56 & 91.8 \\
End-to-end anastomosis wedge & 5 & 8.2 \\
Redo procedure & 12 & 19.7 \\
Conversion to open & 1 & 1.6 \\
Pathology identified on EGD & $\mathbf{n}$ & $(\%$ of 53$)$ \\
Giant hiatal hernia & & 62.3 \\
Esophagitis & 18 & 34.0 \\
Barrett's esophagus & 11 & 20.8 \\
Stricture & 11 & 20.8 \\
Paraesophageal hernia & 5 & 9.4 \\
Wrap breakdown or slipped wrap & 4 & 7.6 \\
Patient characteristics & $\mathbf{n}$ & $(\%$ of 61$)$ \\
Female sex & 33 & 54.1 \\
Male sex & 28 & 45.9 \\
\hline
\end{tabular}

$E G D$, Esophagogastroduodenoscopy.

erative VBE or 3-dimensional computed tomographic scan (3-D CT) to objectively assess the anatomic results of the repair.

To perform analyses, we used JMP for Windows, version 4.0.4 (SAS Institute Inc, Cary, NC). Unless otherwise noted, results are reported as means \pm standard deviation (median).

\section{Surgical Technique}

We placed specific emphasis on meticulous preservation of crural integrity, complete sac excision (Figure E1), routine gastroesophageal fat-pad dissection (Figures 1 and E2), a totally intraabdominal Collis wedge gastroplasty to augment esophageal length (Figures 2 and E3), ${ }^{10}$ and crural repair with pledgeted 0 silk sutures in all patients (Figures 3 and E4). For all 61 patients, we performed a totally intra-abdominal Collis wedge gastroplasty (using simplified endoscopic linear gastrointestinal anastomosis [GIA] or, earlier in the series, endoscopic circular end-to-end anastomosis [EEA] plus linear GIA, stapler techniques) combined with a Nissen fundoplication (Figure E5).

\section{Results}

\section{Demographics}

During our study period, we performed 61 Collis-Nissen wedge gastroplasties (Tables 1 and 2). Of the 61 patients, 12 (20\%) were referred to our institution after previous attempts at repair. The mean time from patients undergoing the operation and this study being performed was $3 \pm 1.11$ years (median, 2.81 years; range, 353 days to 6.01 years). Two (3.3\%) patients experienced minor complications, 2 (3.3\%) experienced major complications, and 1 (1.6\%) died (of myocardial infarction and cardiac arrest). The 2 minor complications were a port-site hematoma and a readmission for bloating. The 2 major complications were a contained staple-line leak (1.6\%), which was successfully managed nonoperatively, and respiratory failure $(1.6 \%)$, which resulted in a prolonged ventilator course. The overall complication rate was $8.2 \%$.
TABLE 2. Procedure summary

\begin{tabular}{lrrr}
\hline & Mean & Median & $\begin{array}{r}\text { Standard } \\
\text { Deviation }\end{array}$ \\
\hline Age (y) & 61.9 & 62.4 & 14.7 \\
Operative time (min) & 308.8 & 274.5 & 103.2 \\
Estimated blood loss (mL) & 52.1 & 45.0 & 43.4 \\
Length of stay (d) & 5.5 & 4.0 & 8.5 \\
\hline
\end{tabular}

\section{Preoperative Evaluation}

We performed preoperative manometry in 22 patients and measured lower esophageal sphincter pressure in $17 \mathrm{pa}-$ tients. The mean lower esophageal sphincter pressure was $13.1 \pm 13.8 \mathrm{~mm} \mathrm{Hg}$ (median, $10.2 \mathrm{~mm} \mathrm{Hg}$ ). We preoperatively monitored 24 -hour $\mathrm{pH}$ in 14 patients: the mean DeMeester score was $95.6 \pm 68.9$ (median, 83.8). We looked at initial VBE findings in $60(98.4 \%)$ of the 61 patients to accurately characterize their pathology. Of the preoperative VBEs, 14 (23.3\%) showed a total intrathoracic stomach, and $18(38.3 \%)$ showed paraesophageal hiatal hernias. In the cohort there were $12(19.7 \%)$ revisions. Similarly, 53 (86.9\%) underwent esophagogastroduodenoscopy (Table 1). We obtained a gastric emptying study to assess motility in 30 (49.2\%): 22 (73.3\%) had normal motility, and $8(26.7 \%)$ had abnormal motility. Patients' symptoms are described in detail in Table 3.

\section{Postoperative Evaluation}

Postoperatively, we evaluated patients on the basis of the questionnaires (Table E1) and the VBE or 3-D CT results. Of the 61 patients, 52 (85.3\%) completed the questionnaire, and 54 (89\%) underwent postoperative imaging to assess for recurrence.

The mean time between patients undergoing the operation and completing the questionnaires was $310.1 \pm 297.4$ days (median, 199 days). Of the 52 patients who completed the questionnaires, $51(98.1 \%)$ stated that they were satisfied with their operation. The mean GERD-HRQOL score was $1.15 \pm 2.78$ (median, 0.0). Only $13(25 \%)$ of the respondents reported using antacid medication of any sort. A full $96.2 \%$ of respondents had GERD-HRQOL composite scores in the excellent range, and only $1.9 \%$ had scores in the poor range. More than $80 \%$ of respondents experienced excellent resolution of their heartburn, regurgitation, chest pain, abdominal pain, and respiratory symptoms (Table 4).

Postoperative imaging evaluation occurred a mean of $1.31 \pm 1.05$ years (median, 1.13 years) after the operation (Figure 4). In all, 54 patients had postoperative radiographic data; $15 \%$ of all postoperative imaging consisted of 3-D CT, and $85 \%$ consisted of VBEs. Of those 54 patients, none had experienced recurrences per the standard 1-month baseline postoperative VBE. At 1 year or more postoperatively, 42 
TABLE 3. Preoperative symptoms

\begin{tabular}{lcc}
\hline Symptoms reported & $\mathbf{n}$ & (\% of 61) \\
\hline Heartburn & 53 & 86.9 \\
Dysphagia & 33 & 54.1 \\
Regurgitation & 33 & 54.1 \\
Atypical symptoms & 39 & 63.9 \\
Respiratory symptoms & 14 & 23.0 \\
Chest pain or pressure & 11 & 18.0 \\
Abdominal pain & 11 & 18.0 \\
Early satiety & 9 & 14.8 \\
Bloating & 2 & 3.3 \\
Vomiting & 2 & 3.3 \\
\hline
\end{tabular}

patients underwent follow-up imaging: 2 (4.7\%) had small asymptomatic recurrences, both of which were seen on the VBE at the 2-year follow-up visit. Both of these patients reported excellent satisfaction and had GERD-HRQOL composite scores of 0 .

\section{Discussion}

Although laparoscopic Nissen fundoplication is now widely applied in the surgical treatment of gastroesophageal reflux disease, many surgeons are less than sanguine about its use for repair of giant hiatal hernias because of reports of high recurrence rates during short-term analysis. When we began performing laparoscopic giant hiatal hernia repair, we strove to recreate as meticulously as possible the open techniques of Maziak and colleagues ${ }^{5}$ and Altorki and associates, ${ }^{11}$ both of whom have demonstrated excellent longterm outcomes with open repair. This report is an analysis of our short-term outcomes in both this group of patients and in those referred with recurrent hiatal hernias. The majority of those with recurrent hernias had large intrathoracic recurrent hernias.

\section{Safety and Symptom Control Efficacy}

In our series complications were comparable with those reported for open repair of giant hiatal hernias. The median

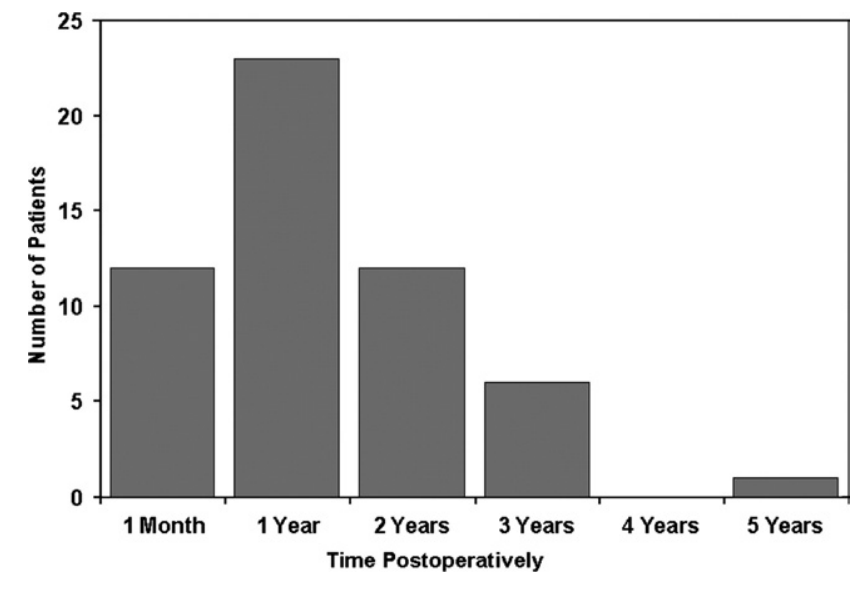

Figure 4. Histogram of postoperative imaging: chronologic breakdown of postoperative imaging of all patients.

age of our patients at the time of operation was 62.4 years. Our incidence of death, $1.6 \%$, was comparable with that reported for both open (1.7\% to $1.86 \%)^{3,6}$ and minimally invasive $(0.5 \% \text { to } 5.4 \%)^{2,9}$ approaches. Our incidence of respiratory failure, $1.6 \%$, was also similar to that reported for both open and minimally invasive approaches. ${ }^{12}$ Our incidence of esophageal leak, $1.6 \%$, was on the low range of that reported for minimally invasive approaches $(0.6 \%$ to $5.4 \%){ }^{2,9,12}$ Thus, our results demonstrate that laparoscopic giant hiatal hernia repair can be performed safely, with minimal morbidity and mortality.

Historically, patients with giant hiatal hernias typically present with gastroesophageal reflux disease; obstructive symptoms, including heartburn (60\% to $87 \%$ ), dysphagia (43\% to $73 \%$ ), regurgitation (47\%), either chest or epigastric pain $(20 \%$ to $47 \%)$, or dyspnea $(37 \%)$, or both. ${ }^{9,13-17}$ Our study echoes these symptomatic indications virtually exactly.

Although indications and symptoms preoperatively have been well described, the postoperative quantification is

TABLE 4. Postoperative symptoms and GERD-HROOL questionnaire scores

\begin{tabular}{|c|c|c|c|c|c|}
\hline & Excellent (\%) & Good (\%) & Fair (\%) & Poor (\%) & Total (\%) \\
\hline \multicolumn{6}{|l|}{ Symptoms reported } \\
\hline Heartburn & 88.5 & 7.7 & 3.9 & 0.0 & 100.0 \\
\hline Dysphagia & 73.1 & 21.2 & 5.8 & 0.0 & 100.0 \\
\hline Regurgitation & 92.3 & 7.7 & 0.0 & 0.0 & 100.0 \\
\hline Chest pain & 96.2 & 1.9 & 0.0 & 1.9 & 100.0 \\
\hline Abdominal pain & 78.9 & 17.3 & 1.9 & 1.9 & 100.0 \\
\hline Respiratory symptoms & 94.2 & 3.9 & 1.9 & 0.0 & 100.0 \\
\hline Bloating & 73.1 & 21.2 & 1.9 & 3.9 & 100.0 \\
\hline Diarrhea & 76.9 & 13.2 & 0.0 & 9.6 & 100.0 \\
\hline Early satiety & 55.8 & 21.2 & 11.5 & 11.5 & 100.0 \\
\hline GERD-HROOL & 96.2 & 1.9 & 0.0 & 1.9 & 100.0 \\
\hline
\end{tabular}

Some patients reported more than 1 symptom. GERD-HROOL, Gastroesophageal Reflux Disease Health-Related Quality of Life questionnaire. 
more difficult. The GERD-HRQOL questionnaire is an objective way to gain quantitative comparable data of patients' subjective symptomatic results. ${ }^{8,9,15}$ Luketich and cowork$\mathrm{ers}^{15}$ reported a mean postoperative GERD-HRQOL composite score of 2.3. In a follow-up series, Pierre and colleagues ${ }^{9}$ reported that $56 \%$ of their patients underwent Collis gastroplasties, $84 \%$ of whom had "excellent" results, per their composite GERD-HRQOL score. Our results were similar. Of our patients who underwent Collis-Nissen wedge gastroplasties, the mean GERD-HRQOL composite score was 1.15. A full $96.2 \%$ of our patients had composite scores in the "excellent" range, and an additional $1.9 \%$ had composite scores in the "good" range. In all, 70\% to $90 \%$ of our patients reported "excellent" results for most of their postoperative symptoms; only 1 patient was unsatisfied with the operation.

\section{Recurrence Rates}

Traditionally, repairs of giant hiatal and paraesophageal hernias have been performed by means of laparotomy or thoracotomy. Recurrence rates after open repair range from unknown ${ }^{18}$ to $1 \%$ to $2 \%{ }^{11,19}$ to $11 \% .^{20}$ In these studies recurrence was determined by means of patient or chart interview and not by objective means. Maziak and colleagues ${ }^{5}$ provided the first large series of repairs with longterm objective assessment for recurrence with VBE. In their series of 75 patients undergoing transthoracic Collis-Belsey repairs, there were no radiographic recurrences, whereas in 15 who underwent only Belsey fundoplication without Collis gastroplasty, the recurrence rate was $2(13 \%)$ of 15 , suggesting the need for liberal use of Collis gastroplasty. This study has set a benchmark for future outcome studies of giant hiatal hernia repair. Patel and associates ${ }^{6}$ have reported the largest series of transthoracic repair of giant hiatal hernia using a Collis gastroplasty with an antireflux procedure in $96 \%$ of 240 patients. These authors also provide long-term follow-up, including $\mathrm{VBE}$, and report a recurrence rate of $12.4 \%$.

It is possible to obtain excellent long-term results without the use of a Collis gastroplasty. Altorki and coworkers ${ }^{11}$ reported a series of 42 patients undergoing Belsey or Nissen fundoplication without Collis gastroplasty. The recurrence was $2(4.8 \%)$ of 42 ; however, this was based only on symptomatic and not objective follow-up. Unique to these authors' technique was the use of extensive esophageal mobilization from the hiatus to the aortic arch, with division of the middle esophageal artery and occasionally the left inferior bronchial artery and the pulmonary branches of the left vagus nerve, allowing them to avoid the use of Collis gastroplasty. In general, in series of open repairs with a Collis gastroplasty, the hernia recurrence rate is $0 \%$ to $12.4 \%, 5,6$ and without a Collis gastroplasty, it is $4.8 \%$ to $15 \%{ }^{3,11}$
In some series laparoscopic giant hiatal hernia repair has shown alarmingly high short-term recurrence rates, ranging from 12.9 to $42 \% .^{2-4}$ Hashemi and colleagues ${ }^{3}$ found recurrence in $12(42 \%)$ of 41 patients undergoing routine postoperative VBE. Dahlberg and associates ${ }^{2}$ found a recurrence rate of $12.9 \%$, discovered on the basis of recurrent symptoms without the use of routine postoperative VBE. In neither of these series was Collis gastroplasty used routinely. Not all authors have experienced such high rates of short-term recurrence. In the series from Pierre and coworkers, ${ }^{9} 5(2.5 \%)$ of 200 patients undergoing laparoscopic repair required reoperation, although routine postoperative barium esophograms were not reported. It would appear that clinical evidence of short-term recurrence is within $2.5 \%$ to $12 \%$, whereas occult radiographic recurrence might be as high as $42 \%$. Although these radiographically occult recurrences might be asymptomatic, we are concerned that despite their lack of symptoms, they portend a high and likely symptomatic long-term clinical recurrence.

Our short-term anatomic recurrence rate of $4.7 \%$ compares favorably with that of open repairs; however, longer follow-up is still required.

\section{Technical Aspects}

Undoubtedly, as with an open repair, the key to improving results of laparoscopic repair is careful attention to operative detail. Because of the size, recurrent nature, or both of these hernias, the complexity of the operation can be significant, and it can be quite easy for a less experienced surgeon to get lost. We follow a standard series of steps in the performance of laparoscopic giant hiatal hernia repair (in patients without previous operations), which markedly augments the conduct of the repair. Our technique focuses on the following steps:

1. Hernia reduction and complete sac excision. The hernia sac is grasped at its apex, inverted by pulling inferiorly, and then opened circumferentially superior to the crura (Figure E1). This allows immediate reduction of the hernia with simple exposure of the mediastinum, which is enhanced by the $\mathrm{CO}_{2}$ insufflation. Generally, it is not necessary to grasp the stomach in an effort to reduce it. By opening the hernia sac superior to the crura, the integrity of the crura and overlying peritoneum are preserved, ensuring the best possible tissues for crural reconstruction. This mimics the open repair performed by means of thoracotomy, whence crural integrity is maintained.

2. Mediastinal circumferential esophageal dissection to $10 \mathrm{~cm}$ or more. Although an excellent degree of esophageal mobilization can be achieved laparoscopically, in most cases it does not approximate that of the open thoracotomy, particularly the technique of Altorki and coworkers. ${ }^{11}$ 
3. Complete circumferential paraesophageal fat-pad dissection (Figure E2). By dissecting the fat pad (and the associated vagus nerves) circumferentially about the esophagogastric junction (EGJ), the EGJ can be clearly identified. Also, circumferential dissection allows placement of the wrap within the fat-pad dissection, adding a further barrier to recurrent herniation. Theoretically, the circumferential highly selective vagotomy that is naturally a part of the fat-pad dissection might help prevent local acid production, a concern raised by some authors. ${ }^{4,14}$

4. Assessment of the position of the EGJ location (Figures 1 and E2). By holding the fundus to the patient's left upper quadrant and bringing the EGJ toward the anterior apex of the crural aperture, a determination of esophageal length can be made. This length is measured with known points on a laparoscopic grasper. When the intra-abdominal esophageal length is found to be less than $2.5 \mathrm{~cm}$, a Collis wedge gastroplasty is performed over a $48 \mathrm{~F}$ bougie (Figures 2 and E3).

5. Crural closure with pledgeted 0 silk sutures with $\mathrm{SH}$ needles (Figures 3 and E4). We prefer these stitches over automatic or assisted sewing devices because the SH needle allows deep and wide bites under direct vision.

6. Performance of a 3-stitch Nissen fundoplication with the wrap placed within the fat-pad dissection and performed over a 52F bougie (Figure E5).

Of note, our initial 5 gastroplasties were performed with EEA; however, we then changed to wedge gastroplasty using the linear endo-GIA. We were concerned about EEA leak with no circumferential purse-string suture application; in addition, the GIA approach is technically less challenging, faster, and uses the already available ports without any enlargement. These 2 concerns have been noted elsewhere. ${ }^{21}$

\section{Potential Drawbacks}

There are several areas of potential concern with this surgical approach: bougie exchange, gastroplasty length, surveillance of Barrett's esophagus, and the use of postoperative antacids.

The reintroduction of the second larger bougie can potentially disrupt the gastroplasty staple line. The angle of the stapler and stapler geometry create a neoesophagus with a diameter a few millimeters larger than that of the $48 \mathrm{~F}$ bougie. ${ }^{5,21,22}$ The reintroduction of a $52 \mathrm{~F}$ bougie permits a fundoplication of appropriate size and is described in the open literature as well ${ }^{23-26}$; however, the passage needs to be performed under direct visualization, with appropriate laparoscopic retraction and with awareness of any undue resistance.
Typically, the maximal length of the wedge gastroplasty has been less than $5 \mathrm{~cm}$. A transthoracic dissection to maximize esophageal mobilization and minimize gastroplasty length should be strongly considered if a gastroplasty of longer than $5 \mathrm{~cm}$ will be required.

Surveillance monitoring of patients with Barrett's metaplasia is more challenging after a fundoplication ${ }^{27,28}$; however, it should still be done and performed following consensus guidelines (4-quadrant biopsies at $1 \mathrm{~cm}$ spacing). ${ }^{29}$ In this series the distance of the original squamocolumnar junction was recorded and used for estimation at repeat endoscopy.

A significant percentage of patients in this series and in previously published reports restart antacid medications postoperatively. This is often done for nonreflux symptoms or without objective evidence of abnormal distal esophageal acid exposure. Probing questions into symptoms and obtaining objective data can elucidate those who truly need acid suppression postoperatively.

\section{Conclusions}

Laparoscopic repair of giant and recurrent hiatal hernias can be performed safely and with excellent short-term results. Meticulous attention to a standard sequence of operative maneuvers and principles allows close approximation of the open technique of repair. Objective anatomic radiographic imaging and symptomatic evaluations (GERD-HRQOL questionnaire) are keys to assessment of results. Liberal application of a Collis wedge gastroplasty might play a role in the lower short-term recurrence rates of this series.

We thank Mary Knatterud, PhD, for her expert editorial assistance with this manuscript.

\section{References}

1. Terry M, Smith CD, Branum GD, Galloway K, Waring JP, Hunter JG. Outcomes of laparoscopic fundoplication for gastroesophageal reflux disease and paraesophageal hernia. Surg Endosc. 2001;15:691-9.

2. Dahlberg PS, Deschamps C, Miller DL, Allen MS, Nichols FC, Pairolero PC. Laparoscopic repair of large paraesophageal hiatal hernia. Ann Thorac Surg. 2001;72:1125-9.

3. Hashemi M, Peters JH, DeMeester TR, Huprich JE, Quek M, Hagen JA, et al. Laparoscopic repair of large type III hiatal hernia: objective followup reveals high recurrence rate. J Am Coll Surg. 2000;190:553-60.

4. Lin E, Swafford V, Chadalavada R, Ramshaw BJ, Smith CD. Disparity between symptomatic and physiologic outcomes following esophageal lengthening procedures for antireflux surgery. $J$ Gastrointest Surg. 2004;8:31-9.

5. Maziak DE, Todd TR, Pearson FG. Massive hiatus hernia: evaluation and surgical management. J Thorac Cardiovasc Surg. 1998;115:53-62.

6. Patel HJ, Tan BB, Yee J, Orringer MB, Iannettoni MD. A 25-year experience with open primary transthoracic repair of paraesophageal hiatal hernia. J Thorac Cardiovasc Surg. 2004;127:843-9.

7. Pearson FG. Complications and pitfalls: Belsey and Collis-Belsey antireflux repairs. Chest Surg Clin N Am. 1997;7:513-32.

8. Velanovich V, Vallance SR, Gusz JR, Tapia FV, Harkabus MA. Quality of life scale for gastroesophageal reflux disease. $J$ Am Coll Surg. 1996;183:217-24. 
9. Pierre AF, Luketich JD, Fernando HC, Christie NA, Buenaventura PO, Litle VR, et al. Results of laparoscopic repair of giant paraesophageal hernias: 200 consecutive patients. Ann Thorac Surg. 2002;74:1909-15.

10. Hoang CD, Koh PS, Maddaus MA. Short esophagus and esophageal stricture. Surg Clin North Am. 2005;85:433-51.

11. Altorki NK, Yankelevitz D, Skinner DB. Massive hiatal hernias: the anatomic basis of repair. J Thorac Cardiovasc Surg. 1998;115:828-35.

12. Andujar JJ, Papasavas PK, Birdas T, Robke J, Raftopoulos Y, Gagne DJ, et al. Laparoscopic repair of large paraesophageal hernia is associated with a low incidence of recurrence and reoperation. Surg Endosc. 2004;18:444-7.

13. Low D, Unger T. Open repair of paraesophageal hernia: reassessment of subjective and objective outcomes. Ann Thorac Surg. 2005;80:287-94.

14. Jobe BA, Horvath KD, Swanstrom LL. Postoperative function following laparoscopic collis gastroplasty for shortened esophagus. Arch Surg. 1998;133:867-74.

15. Luketich JD, Raja S, Fernando HC, Campbell W, Christie NA, Buenaventura PO, et al. Laparoscopic repair of giant paraesophageal hernia: 100 consecutive cases. Ann Surg. 2000;232:608-18.

16. Neuhauser B, Hinder RA. Laparoscopic reoperation after failed antireflux surgery. Semin Laparosc Surg. 2001;8:281-6.

17. Swanstrom LL, Jobe BA, Kinzie LR, Horvath KD. Esophageal motility and outcomes following laparoscopic paraesophageal hernia repair and fundoplication. Am J Surg. 1999;177:359-63.

18. Geha AS, Massad MG, Snow NJ, Baue AE. A 32-year experience in 100 patients with giant paraesophageal hernia: the case for abdominal approach and selective antireflux repair. Surgery. 2000;128:623-30.
19. Allen MS, Trastek VF, Deschamps C, Pairolero PC. Intrathoracic stomach. Presentation and results of operation. $J$ Thorac Cardiovasc Surg. 1993;105:253-8.

20. Williamson WA, Ellis FH Jr, Streitz JM Jr, Shahian DM. Paraesophageal hiatal hernia: is an antireflux procedure necessary? Ann Thorac Surg. 1993;56:447-51.

21. Terry ML, Vernon A, Hunter JG. Stapled-wedge Collis gastroplasty for the shortened esophagus. Am J Surg. 2004;188:195-9.

22. Johnson AB, Oddsdottir M, Hunter JG. Laparoscopic Collis gastroplasty and Nissen fundoplication. A new technique for the management of esophageal foreshortening. Surg Endosc. 1998;12:1055-60.

23. Orringer MB, Orringer JS. The combined Collis-Nissen operation: early assessment of reflux control. Ann Thorac Surg. 1982;33:534-9.

24. Orringer MB, Sloan H. Combined Collis-Nissen reconstruction of the esophagogastric junction. Ann Thorac Surg. 1978;25:16-21.

25. Stirling MC, Orringer MB. The combined Collis-Nissen operation for esophageal reflux strictures. Ann Thorac Surg. 1988;45:148-57.

26. Stirling MC, Orringer MB. Continued assessment of the combined Collis-Nissen operation. Ann Thorac Surg. 1989;47:224-30.

27. Abbas AE, Deschamps C, Cassivi SD, Allen MS, Nichols FC 3rd, Miller DL, et al. Barrett's esophagus: the role of laparoscopic fundoplication. Ann Thorac Surg. 2004;77:393-6.

28. O'Riordan JM, Byrne PJ, Ravi N, Keeling PW, Reynolds JV. Longterm clinical and pathologic response of Barrett's esophagus after antireflux surgery. Am J Surg. 2004;188:27-33.

29. Sampliner RE. Updated guidelines for the diagnosis, surveillance, and therapy of Barrett's esophagus. Am J Gastroenterol. 2002;97: 1888-95. 


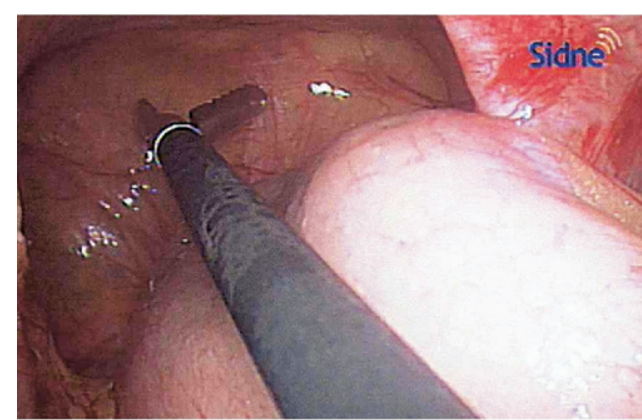

A

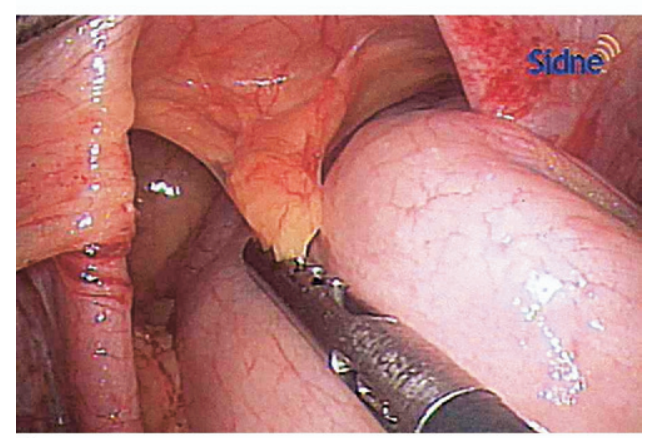

B

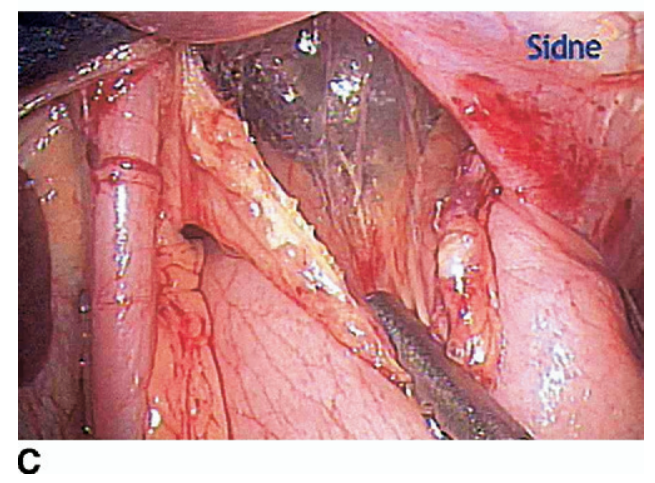

Figure E1. A and B, The grasper reaches into the hernia sac and everts it. C, The sac is incised superior to the crura to preserve crural peritoneal lining and to start mediastinal dissection. The pneumoperitoneum aids with the dissection.

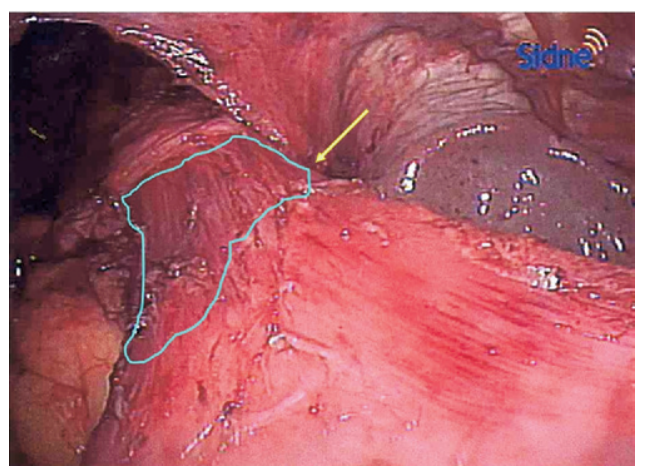

Figure E2. The gastroesophageal junction (yellow arrow) is at the level of the hiatus after extensive mediastinal mobilization and dissection of the paraesophageal fat pad (image shown under tension). The blue line delineates the area originally covered by the fat pad. 

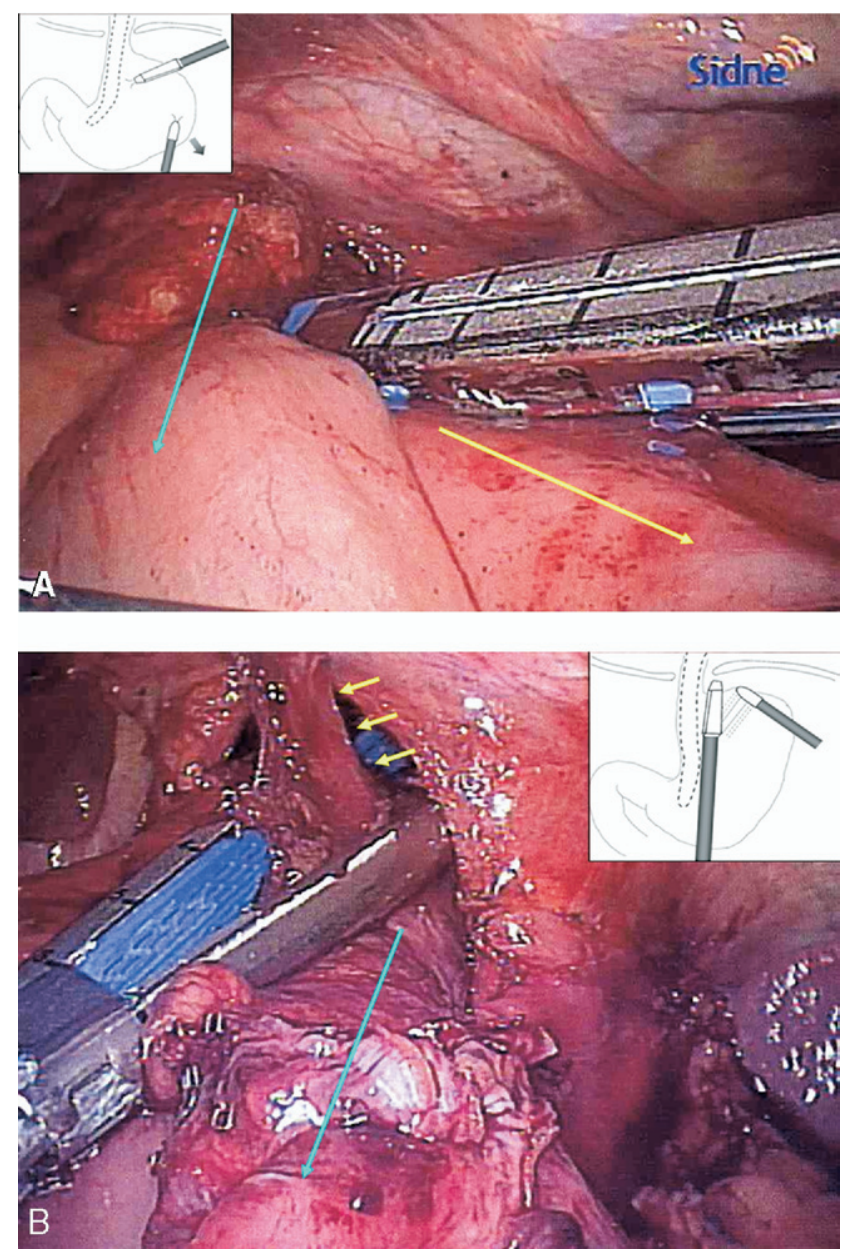

Figure E3. A, The fundus is now retracted inferiorly and to the patient's left side (yellow arrow). The blue arrow shows the alignment of the dilator along the lesser curvature. The stapler is introduced through a left upper quadrant port. B, The gastric wedge (yellow arrows) is transected with a stapler from the right upper quadrant. The staple line has to be fit snuggly against the dilator (blue arrow). Line drawing insets are presented for visualization. ${ }^{10}$

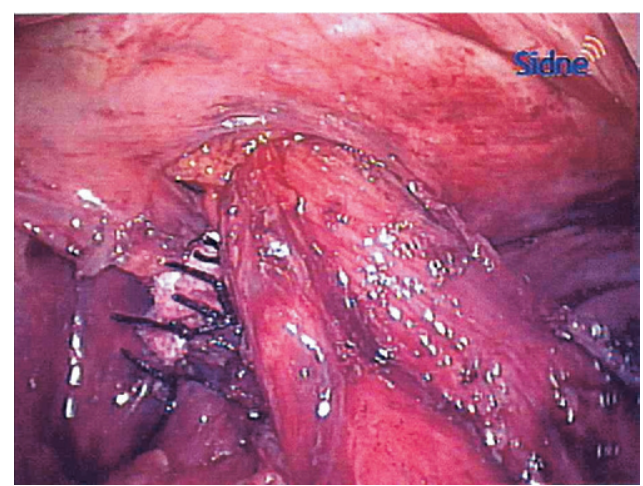

Figure E4. Completed crural repair.

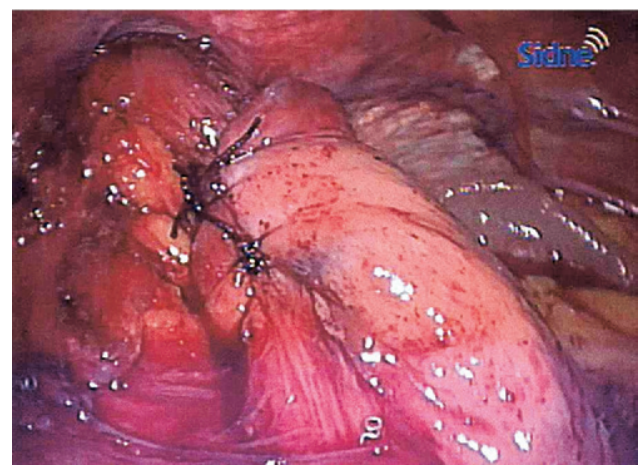

Figure E5. Completed Nissen fundoplication. 
TABLE E1. GERD-HROOL questionnaire ${ }^{8,9}$ and symptom assessment questionnaire

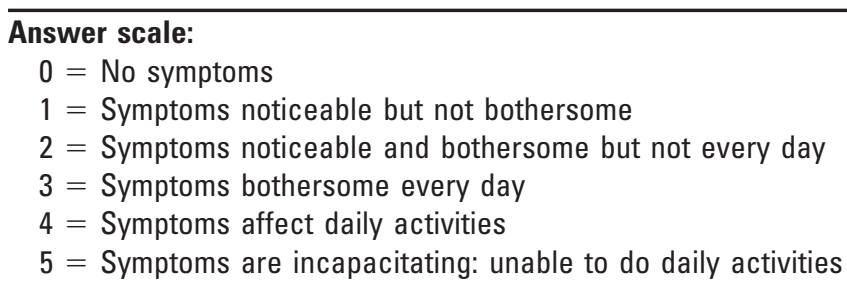

\section{Question}

How bad is the heartburn?

Heartburn when lying down?

Heartburn when standing up?

Heartburn after meals?

Does heartburn change diet?

Does heartburn wake you from your sleep?

Do you have difficulty swallowing?

Do you have pain with swallowing?

If you take medication, does this affect your daily life?

0
0
0
0
0
0
0
0
0

Are you satisfied with your present condition? Satisfied/dissatisfied

\section{Answer scale:}

$0=$ Excellent outcome: no symptoms present

$1=$ Good outcome: symptoms present but mild

$2=$ Fair outcome: symptoms present but controlled with medications or nonsurgical interventions

$3=$ Poor outcome: symptoms unimproved or worse

\section{Symptom}

Heartburn

Difficultly swallowing (dysphagia)

Regurgitation

Chest pain

Abdominal pain

Respiratory symptoms

Bloating

Diarrhea

Feeling full early in your meal (early satiety)

$\begin{array}{lllll}0 & 1 & 2 & 3 \\ & 0 & 1 & 2 & 3 \\ 0 & 1 & 2 & 3 \\ 0 & 1 & 2 & 3 \\ 0 & 1 & 2 & 3 \\ & 0 & 1 & 2 & 3 \\ & 0 & 1 & 2 & 3 \\ & 0 & 1 & 2 & 3 \\ & 0 & 1 & 2 & 3\end{array}$

GERD-HROOL, Gastroesophageal Reflux Disease Health-Related Quality of Life questionnaire. 